\title{
Dural Arteriovenous Fistula - A Review
}

\section{SHARI F UDDI N KHAN ${ }^{1}$, MD. MAHMUDUR RAHMAN SIDDIQUI ${ }^{2}$, KAZ MOHI BUR RAHMAN, ${ }^{1}$ MD. AZHARUL HOQUE, ${ }^{3}$ MD. BADRUL ALAM MONDOL, ${ }^{3}$ MANSUR HABIB, ${ }^{4}$ QUAZ DEEN MOHAMMAD 4}

\begin{abstract}
Introduction
Dural arteriovenous fistulas (AVF) are pathologic abnormal vascular connections located with in the walls of a dural sinus or an adjacent cortical vein, which can have profound detrimental effects on the underlying brain and cranial nerves. ${ }^{1,2}$ Dural arteriovenous fistulas (DAVF) may occur in the intracranial and spinal compartments of the central nervous system. ${ }^{3}$ Most frequently affecting the region of the transverse and cavernous sinuses, intracranial DAVFs uncommonly involve the dura of the craniocervicaljunction. ${ }^{4-}$ ${ }^{6}$ There remains some confusion and debate regarding proper nomenclature, pathophysiology, pathoetiologic mechanisms with other central nervous system vascular malformations, But this particular type of arteriovenous shunting malformation has been referred to as both dural AVF and dural AVM (arteriovenous malformation) ${ }^{7-10}$ Intracranial dural AVF accunt for $10-15 \%$ of all intracranial artriovenous lesions but no correlation was observed between age and frequency of aggressive neurologic symptoms. ${ }^{2,6,11,12}$ But there is a higher incidence in women, with a peak incidence occurring in between 30 to 50 years of age. ${ }^{13,14}$ Dural AVF can affect a variety of cerebral venous structures, which can present at various clinical stages, ranging from a simple irritating pulsesynchronous bruit, tinnitus to a disabling neurological deficit as a result of ischaemia from impaired venous drainage to life threatening intracranial hemorrhage from venous hypertension. ${ }^{15,16}$ So a good understanding of the natural history of dural AVF is fundamental to decision making about treatment.
\end{abstract}

\section{Causal factors}

The exact cause for the development of dural AVF is not clearly known. In particular, it is generally well acknowledged that most dural AVFs are acquired lesions. Various causes of acquired dural AVF have been proposed, most related to the known associated conditions and diseases like trauma, surgery, infection, certain disease entities such as Osler Weber Rendue disease and even pregnancy. ${ }^{17-20}$ Congenital form of dural AVF also have been rarely described in the literature. One popular but highly debatable pathoetiologic mechanisms relates the event of dural sinus thrombosis, in which preexisting physiologic arteriovenous shunts convert to pathologic shunts. ${ }^{17,21} \mathrm{~A}$ number of similar cases have been seen in which dural sinus thrombosis was angiographically documented before the development of a dural AVF. ${ }^{2,22,23}$ It is thought that dural sinus thrombosis enlarges normally present microscopic arteriovenous shunts in the wall of the sinus or stimulates the development of these shunts. The link between dural AVF development and dural sinus thrombosis in bidirectional because a large number of dural Avfs display thrombosis of the adjacent dural sinus or partial thrombosis at the fistula site. ${ }^{2}$ The observed thrombosis may be the result of the high turbulent flow through the fistula or may be the residue of prior thrombosis. ${ }^{2,24}$

\section{Pathology and pathophysiology}

In cerebral dural AVF, venous hypertension or sinus thrombosis may alter the balance of pro-angiogenic and antiangiogenic substances produced by the brain or the dura. ${ }^{25}$ Whether one or more angiogenic factors, such as basic fibroblastic growth factor (bFGF) or vascular endothelial growth factor are causative agents for dural AVF genesis or whether the production of these agents is modulated by the hemodynamic conditions existing with and around the fistula is unclear. ${ }^{17,26}$ Venous hypertension has also been linked to passive congestion and resultant decreased cerebral perfusion and ischaemia. The gene responsible for production of vascular endothelial growth factor, has been shown to contain a hypoxia sensitive response element in it's promoter region. ${ }^{27}$ So, venous hypertension induced ischemia may promote angiogenesis not by a hemodynamic stimulus but also by virtue of the resultant ischemia and hypoxia of the underlying cortex. Such as would be found in a thrombosed sinus. If angiogenic substances are responsible, then recent advances in antiangiogenic mediators may be used as anadjuvant therapy for patients of untreatable dural AVF. ${ }^{28}$

Histopathologic analysis of surgical specimen of transverse and sigmoid sinus of dural AVFs showed intimal thickening of the involved sinuses, arteries and veins with obliteration of the elastic lamina. ${ }^{29}$ Hinokuma et al reported enlarged cortical draining vessels with intimal thickening and elastosis in the wall of the involved dural sinuses. ${ }^{30,31}$ Graeb and Dolman found loose fibrous tissue containing large vascular

1. Assistant Professor, Department of Neurology, Dhaka Medical College, Dhaka

2. Postgraduate resident, Department of Medicine, Dhaka Medical College Hospital, Dhaka.

3. Associate Professor, Department of Neurology, Dhaka Medical College, Dhaka.

4. Professor, Department of Neurology, Dhaka Medical College, Dhaka.

Correspondence: Dr. Sharif Uddin Khan, Assistant Professor, Department of Neurology, Dhaka Medical College, Dhaka. E-mail: sharif.911@gmail.com 
channels with in an occluded superior sagittal sinus. ${ }^{32}$ The site of the DAVF was proposed to be within the wall of the sinus rather than in the sinus. Stenosis of the dural sinus lumen was thought to be secondary to intimal thickening and the emergence of abnormal vessels within the sinus walls. ${ }^{31,32}$

\section{Classification:}

Various classification methods have been adopted that attempt to explain the significance of the angiographic anatomy; namely, the pattern of venous drainage and the clinical presentation and outcome. The commonly used classification systems are shown in Tables 1. Djindjian et al proposed a three-tiered system of classification. ${ }^{33,34}$ Type 1 lesions drain by the ipsilateral sinus; type 2, toward the contra lateral sinus; and type 3 , by cortical veins. From this classification we can predict the severity of the presenting symptoms and the risk for intracranial hemorrhage. Patient with type 1 lesions are at low risk and usually present with headache or bruits and rarely neurologic deficits or hemorrhage. Patient with type 2 lesions are at high risk hemorrhage, especially if the contralateral sinus is hypoplastic or stenotic. Patient with type 3 lesions are at highest risk of brain infarction and hemorrhage.

However, the Cognard system is more detailed and elaborates on the direction of flow, whether normal (anterograde) or retrograde and the presence or absence of cortical venous recruitment. ${ }^{5}$ Such definition enables more accurate comparison of clinical and radiological parameters. In addition, spinal perimedullary venous drainage is specifically recognized. ${ }^{5}$ With only three sub-types the Borden classification is user friendly. In a retrospective review of 102 DAVFs in 98 patients Davies et al. reported a significant correlation between Borden type and clinical presentation. ${ }^{5}$

The progression of disease severity with lesion type was tracked in Cognard's cohort of 205 patients. 27 patients had a type IIa fistula. Of these, 10 (37\%) had aggressive clinical symptoms manifested as headache, papilloedema or visual disturbance. In the 10 patients with type IIb DAVFs, 3 (30\%) followed an aggressive course. 12 of 18 (67\%) patients with type II a+b disease showed aggressive symptoms, including an intracranial haemorrhage in 1 case. 19 (76\%) of 25 patients with type III disease had aggressive symptoms, including 10 (40\%) presenting with haemorrhage. Twenty nine patients had type IV DAVFs with direct venous drainage into a cortical vein with ectasia. Of these, 28 (97\%) had aggressive symptoms, of which 19 (66\%) had haemorrhage. ${ }^{5,17} 6$ of these patients had symptoms attributable to mass effect from the ecstatic vein. The presence of direct cortical venous drainage was therefore a strong predictor of haemorrhage. Of those 12 patients with spinal perimedullary venous drainage, 6 presented with myelopathy. 5,17

Table 1: Proposed grading systems for dural arteriovenous fistulas.

\begin{tabular}{|c|c|c|}
\hline Article & Grade & Pattern of Venous Drainage \\
\hline \multirow[t]{3}{*}{ Djindjian et al ${ }^{33,34}$} & 1 & *Venous drainage to the ipsilateral sinus \\
\hline & 2 & *Venous drainage to the contralateral sinus \\
\hline & 3 & *Venous drainage via cortical veins \\
\hline \multirow{4}{*}{$\begin{array}{l}\text { University of } \\
\text { California at } \\
\text { san Francisco }\end{array}$} & 1 & $\begin{array}{l}\text { *No venous restriction, normal antegrade venous drainage without retrograde or cortical } \\
\text { venous drainage }\end{array}$ \\
\hline & 2 & *Antegrade and retrograde venous drainage with or without cortical venous drainage \\
\hline & 3 & *Retrograte and cortical venous drainage with or without antegrade venous drainage \\
\hline & 4 & $*$ Cortical venous drainage only \\
\hline \multirow[t]{3}{*}{ Borden $^{17}$} & 1 & $\begin{array}{l}\text { * DAVF drainage into a dural venous sinus or meningeal vein with normal anterograde flow. } \\
\text { Usually benign clinical behaviour. }\end{array}$ \\
\hline & 2 & $\begin{array}{l}\text { * Anterograde drainage into dural venous sinus and onwards but retrograde flow } \\
\text { occurs into cortical veins. May present with haemorrhage }\end{array}$ \\
\hline & 3 & $\begin{array}{l}\text { * Direct retrograde flow of blood from the fistula into cortical veins causing venous } \\
\text { hypertension with a risk of haemorrhage. }\end{array}$ \\
\hline \multirow[t]{8}{*}{ Cognard et al ${ }^{5}$} & I & *Venous drainage into a sinus, normal antegrade flow \\
\hline & II & *Venous drainage into a sinus, with insufficient antegrade flow and reflux \\
\hline & $\mathrm{a}$ & - Retrograde venous drainage into a sinus only \\
\hline & b & - Retrograde venous drainage into a cortical vein only \\
\hline & $\mathrm{a}+\mathrm{b}$ & - Retrograde venous drainage into a sinus and cortical veins \\
\hline & III & *Venous drainage in to a cortical vein without ectasia \\
\hline & IV & $\begin{array}{l}\text { *Venous drainage directly into a cortical vein with venous ectasi Larger than } 5 \mathrm{~mm} \text { diameter } \\
\text { and three times larger than the diameter of the draining vein }\end{array}$ \\
\hline & $\mathrm{V}$ & *Venous drainage into spinal perimedullary veins \\
\hline
\end{tabular}




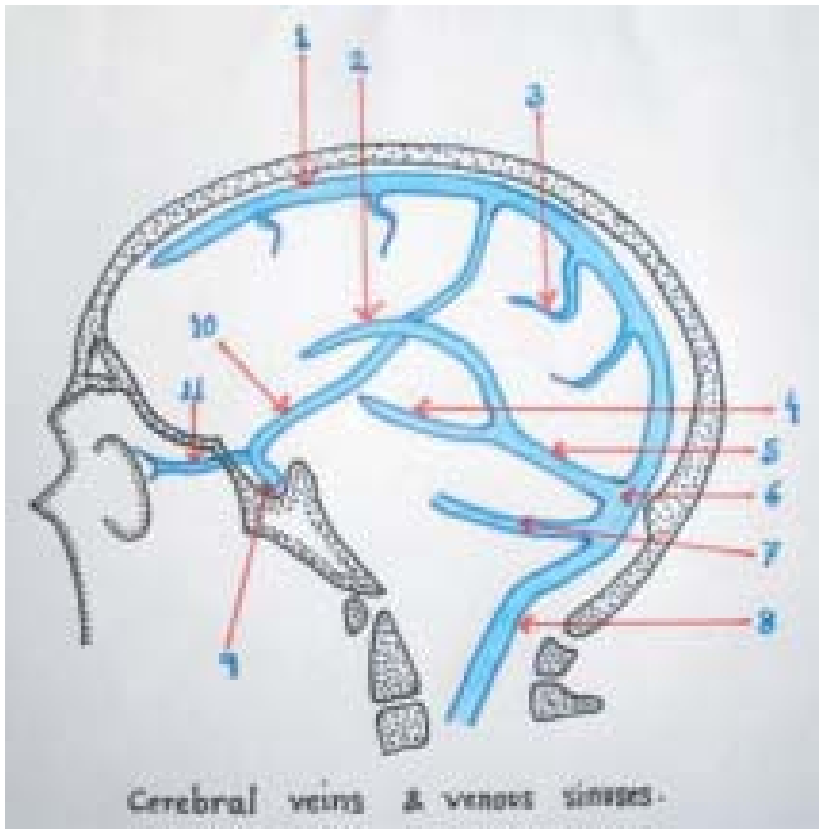

Fig.-1: Cerebral veins and venous sinuses.

1 - Superior sagittal sinus,

2 - Inferior sagittal sinus,

3 - Superior cerebral veins (bridging veins)

4 - Great cerebral vein (of Galen)

5 - Straight sinus,

6 - Confluence of the sinuses,

7 - Transverse sinus,

8 - Sigmoid sinus,

9 - Cavernous sinus,

10 - Superior anastomotic vein (Labbe's vein)

11 - Superior ophthalmic vein.

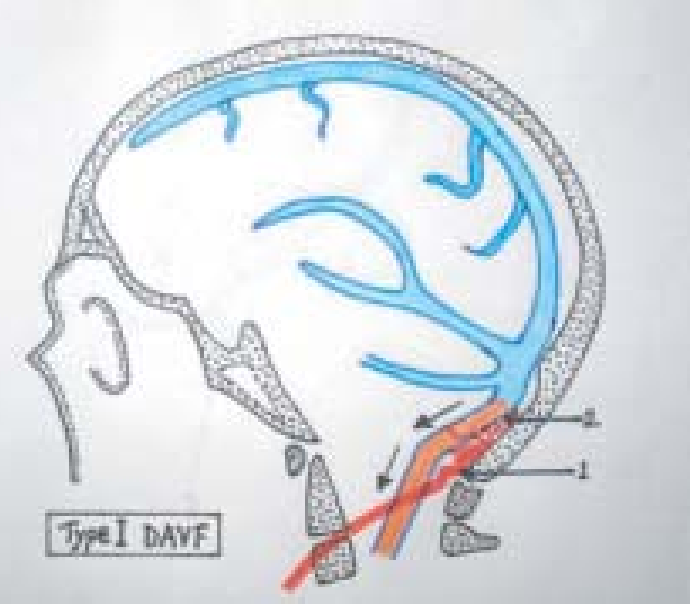

Fig-2: Cognard Type 1 Dural AVF.

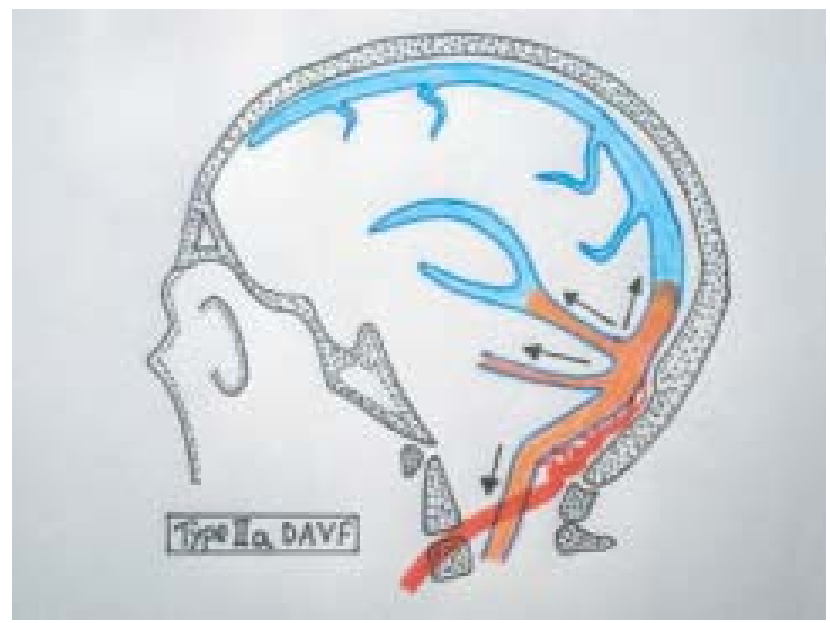

Fig.-3: Cognard Type 2a Dural AVF.

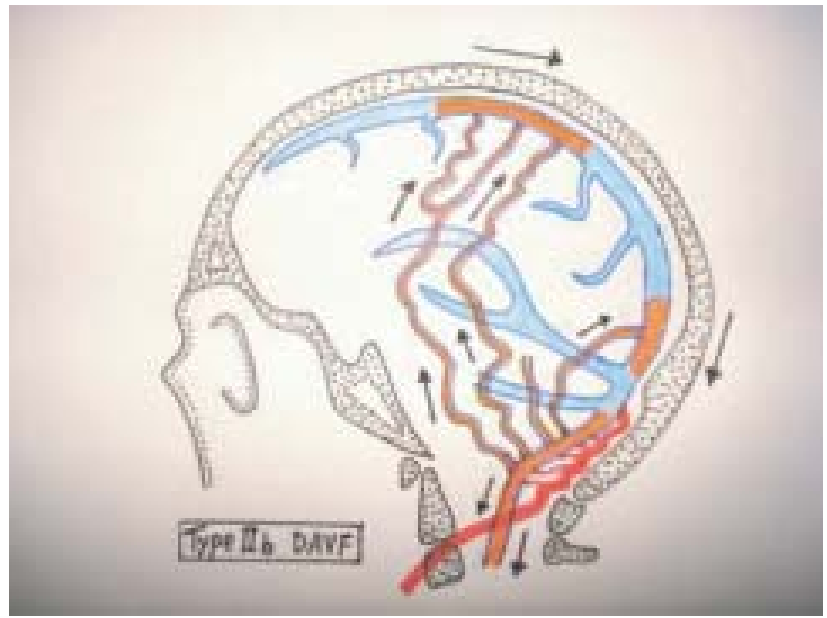

Fig.-4: Cognard Type 2b Dural AVF.

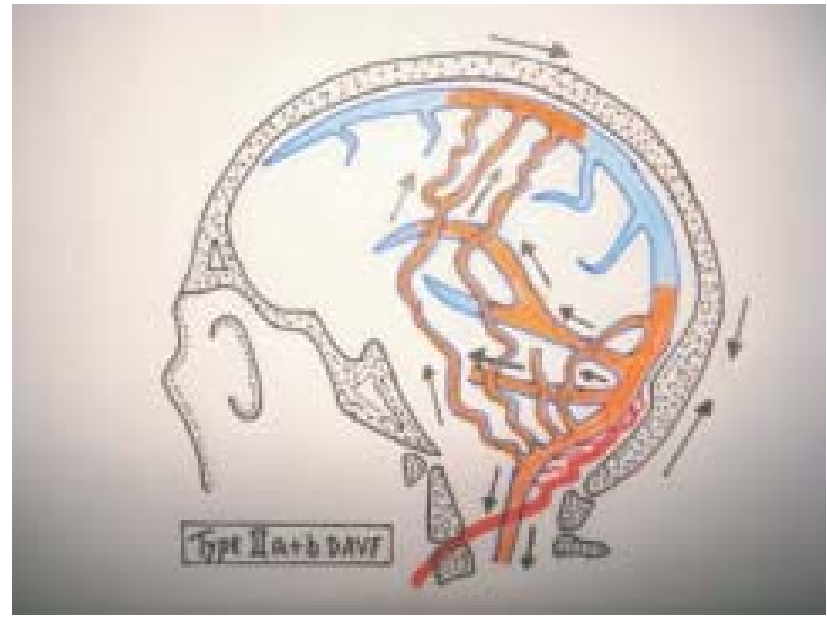

Fig.-5: Cognard Type 2a+b Dural AVF. 


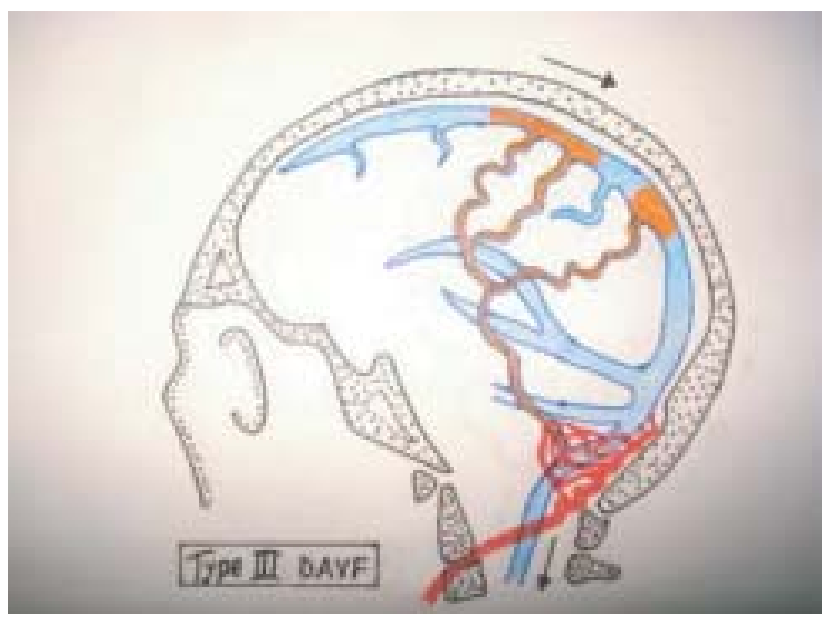

Fig.-6: Cognard Type 3 Dural AVF.

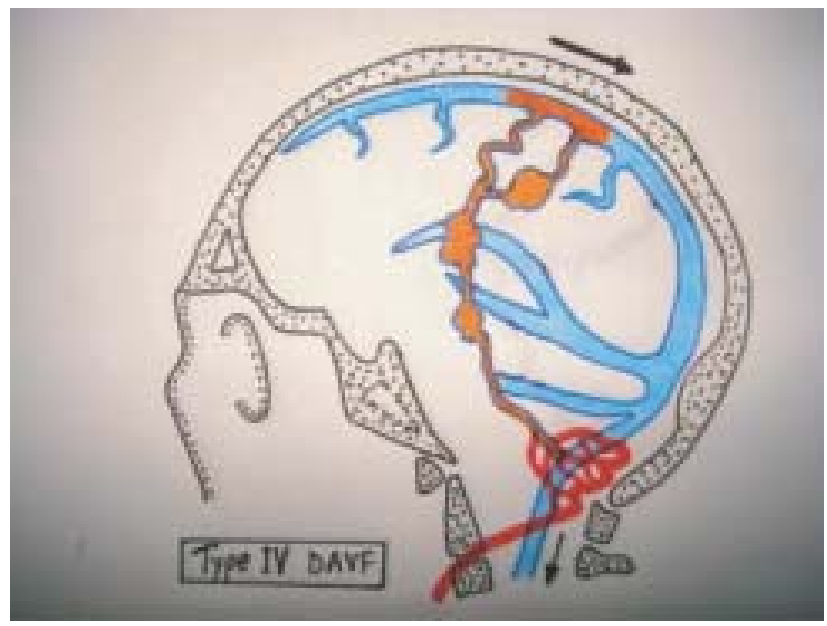

Fig-7: Cognard Type 4 Dural AVF.

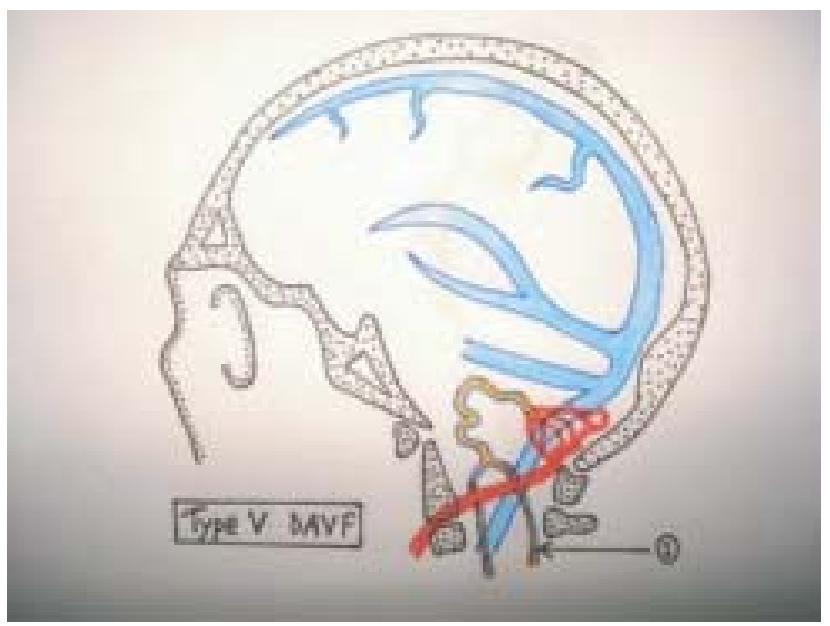

Fig.-8: Cognard Type 5 Dural AVF.
Presentation and natural history:

A wide spectrum of symptoms exists, ranging from the benign to the more aggressive, depend on the specific location of the lesion, extent of arterial supply and specific pattern of venous drainage. ${ }^{17,35}$ Diagnosis may be difficult without imaging but DAVF should be suspected in patients who present with tinnitus, cranial bruit, and signs of raised intracranial pressure such as headache, blurred vision, bilateral papilloedema, and atrophic optic disc. Individual lesions may regress spontaneously or follow a benign course over years. Drainage of a petrous region DAVF to the transverse or sigmoid sinus commonly produces pulsatile tinnitus, sometimes in association with an audible bruit. ${ }^{6}$ Ocular manifestations (eg; opthalmo-plagia, proptosis, chemosis, decreased visual acuity) arecommonly seen with carotid-cavernous fistulas. ${ }^{17,36}$ Treatment is usually undertaken to protect against ocular and visual complications. $^{36}$

More aggressive form of DAVF may manifest as focal neurological deficits, seizure, headache, a dementia-type of syndrome or cerebral haemorrhage, including subarachnoid, subdural or intraparenchymal bleeds. ${ }^{17,37}$ Such features are usually considered to be due to venous hypertension, although neurological deficits may be secondary to arterial steal. ${ }^{17}$ In a meta-analysis of 360 dural AVFs the tentorial incisura was the most ominous location, with 31 out of 32 cases associated with haemorrhagic or non haemorrhagic stroke. ${ }^{17,37}$ However the pattern of venous drainage was considered of paramount importance in predicting aggressive behaviour. Angiographic features that appear to be associated with aggressive behaviour comprise leptomeningeal retrograde venous drainage, variceal or aneurysmal venous structures, and galenic venous drainage. Treatment of DAVFs with these features warrants serious consideration. ${ }^{17,37,38}$ The risk of conversion from a benign to an aggressive DAVF is small but sufficient to warrant repeat angiography if the clinical picture appears to progress. ${ }^{38}$

\section{Imaging:}

CT, MRI and angiography all have roles to play in the investigation of patients with a possible DAVF. Because the clinical and imaging features can be non-specific, the diagnosis of a DAVF is often delayed or missed, but for detection of these fistulas, digital subtraction angiography is the method of choice, allowing the dynamic assessment of cerebral circulation. ${ }^{39}$ Occasionally plain films can demonstrate grooving within the skull vault due to chronic compression from enlarged middle meningeal vessels. ${ }^{17}$ If haemorrhage is suspected, non-enhanced CT is a prerequisite. Venous congestion may appear as an area of low 
density on CT. In most institutions CT is more readily available and cheaper than MRI and so becomes the first-line investigation of patients presenting with tinnitus, headache or other vague neurological symptoms. Multi-detector CT angiography (MDCTA) can now provide high resolution detail of vascular anatomy. ${ }^{39} \mathrm{~T} 2$ weighted MRI is more sensitive to the white matter changes of venous congestion or infarction when compared to CT. It has the drawback of being less sensitive to the changes of acute haemorrhage. If dilated cortical veins are present they may be seen on conventional spin echo sequences and visualised using MR angiographic techniques such as phase contrast venography or contrast enhanced MR angiography. ${ }^{39,40}$ Carotid duplex sonography can be used as the initial screening tool for diagnosis in patients having symptoms related to dural AVFs. ${ }^{41}$

Benign disease, without cortical venous reflux can be missed using both CT and MRI, if there is a strong clinical suspicion of a fistula, Digital subtraction angiography (DSA) is the method of choice for detection of cerebral dural arteriovenous fistulas. A recently introduced contrastenhanced two-dimensional dynamic MR angiographic technique allows projection images similar to those obtained by radiographic DSA to be acquired at a subsecond frame rate with a high in-plane resolution. ${ }^{39,40}$

\section{Treatment:}

Treatment is dependent on the clinical picture, temporal progression and the grade of fistula. ${ }^{42}$ A multidisciplinary approach involving a interventional neurologist, neurosurgeon and neuroradiologist is required. High risk radiographic features, such as cortically diverted venous drainage, patient with visual loss, hemorrhage or infarction require prompt therapy. Treatment options generally involve disrupting the abnormal vascular conduits by using a combination of modalities, including surgical disconnection, radiosurgery, and transarterial and transvenous embolization. The goal of treatment of high risk fistulas should be complete obliteration. On the other hand low risk fistulas can be treated conservatively.

\section{Conservative treatment:}

There are many reported cases of spontaneous regression of dural AVFs, which might be caused by thrombosis of the sinus or fistula, is frequently associated with cavernous sinus dural AVFs; therefore, some dural AVFs can be treated conservatively if benign in nature. ${ }^{6,43}$ These patients are also instructed to avoid antiplatelet agents (aspirin, NSAID), because these would interfere with blood clot formation and spontaneous closure. Occipital artery or carotid artery manual compressions have been reported to occasionally lead to obliteration of the DAVFs, but this procedure has some life threatening complications.

\section{Radiation therapy:}

Recent studies of the efficacy of stereotactic radiosurgery have reported relatively good results, with complete occlusion in $44 \%-87 \%$ of cases without serious complications. 6,44,45 Advantages of this technique include less invasive and fewer short-term complications, whereas a disadvantage is the delayed response (approximately 6-12 months) after irradiation. The combined use of stereotactic radiosurgery and transarterial embolization (TAE) with particles can enhance the effectiveness of this technique and reduce the risk of complications during the follow-up period. ${ }^{6,46}$ The careful use of radiosurgery seems justified when other approaches, including embolization and microsurgery have failed.

\section{Endovascular intervention:}

TAE with Particles:

Transarterial embolization of feeding artery through external carotid branches with particle can easily performed, which can reduce shunt flow. However, complete cures are difficult from this method because of the existence of feeding arteries that cannot be catheterized and the recruitment of a blood supply from collateral arteries. ${ }^{47}$ Therefore, this method is generally used to relieve symptoms or in combination with other procedures such as irradiation, surgery, or transvenous embo-lization (TVE). ${ }^{6,48}$ Several agents are available to embolize; likes, polyvinyl alcohol particles, liquid adhesive (N-butyl-cyanoacrylate) and absolute dehydrated ethanol $(\mathrm{EtOH})$.

\section{Transvenous Coil Embolization:}

This embolization must be considered in patients with fistulas of the transverse and sigmoid sinuses. For curative purposes TVE with coils is used and many studies have reported it to be very useful (complete occlusion in $80 \%-100 \%$ of cases). ${ }^{6,49}$ But this procedure sometimes associated with, serious complications like; vessel injury and intracranial hemorrhage have also been reported. ${ }^{49}$ Inadequate embolization leads to a worsening of symptoms. Critical assessment of diagnostic images and clinical conditions is also important for successful procedures. Previously this procedure was performed by direct surgical or transfemoral introduction of thrombogenic material into fistulae. ${ }^{51}$

TAE with n-butyl-2-cyanoacrylate:

TAE with $n$-butyl-2-cyanoacrylate has been applied to complex dural AVFs that are not accessible with percutaneous transvenous catheterization. Some authors emphasize 
techniques that involve wedging a microcatheter into the main feeding artery to inject a diluted (20\%-25\%) mixture of $n$-butyl-2- cyanoacrylate and iodized oil, and the preparatory devascularization of other minor feeding arteries by embolization with polyvinyl alcohol particles to avoid fragmentation of the glue column by competing inflows. ${ }^{52}$ Although results are relatively good, TAE with $n$-butyl-2cyanoacrylate requires experience in using this material, and some authors have reported a 5\%-20\% complication rate. ${ }^{53}$ Other options such as surgical approaches and a combination of TAE and radiosurgery should also be considered when treating complex dural AVFs.

\section{Stent Placement:}

Recently, in a small number of patients are treated with stent placement with restrictive changes of the sinuses in the treatment of dural AVFs. ${ }^{54}$ Theoretically, the radial force of the stent can restore antegrade sinus flow and close shunts within the sinus wall. Some dural AVFs have been successfully treated with stents, but the long-term results are not yet known. Currently available stents with sufficient diameter are relatively large (over 6 F) and have a stiff shaft. Although this procedure has some difficulties during introduce the stent into the affected area of the sinus due to the acute angle of the sigmoid sinus and the irregular narrowing of the lesion.

\section{Surgery:}

Nowadays interventional procedures have become a firstline treatment for dural AVFs. ${ }^{6}$ Surgical treatment of DAVFs is considered primarily for lesions that have presented with hemorrhage or which have prominent cortical venous drainage and are believed surgically accessible. ${ }^{55}$ However, some difficult cases require surgical techniques (eg, sinus isolation and resection) in combination with interventional procedures. Other cases, dural AVFs of the anterior cranial fossa involved, can be treated more easily and safely with surgical disconnection of the venous drainage. ${ }^{56}$ The goal of the operation is to physically interrupt arterial channels within the dura mater that directly enter the involved sinuses. ${ }^{57}$ A new technique for the treatment of dAVFs is use, in which the affected sinuses are skeletonized and isolated with the placement of a dural interpositional graft. This modification can be useful in preventing the recurrence of fistulas by imposing a mechanical barrier between native dura mater and the sinus while maintaining the patency of the involved sinuses. ${ }^{57}$

\section{Conclusion}

Dural AVF is one of the potentially complex disease of nervous system with a wide range of clinical presentation.
Location of the lesions is very important in determining the presentation, treatment facilities and prognosis. For proper treatment, it is ideal to do cerebral DSA. Which gives us detail information's about the lesion. In the past, dural AVFs have been treated with a variety of approaches, including surgical resection, venous clipping, transcatheter embolization, radiation therapy, or a combination of these treatments. But now a day endovascular approach can be used exclusively in case of DAVFs in cavernous, inferior petrosal and marginal sinus, on the other hand open surgery is the choice in case of DAVF in ethmoidal dural region. Proper knowledge of drainage patterns, the risk of aggressive symptoms, recent technical advances, and current treatment strategies is essential for the treatment of intracranial dural AVFs.

\section{Conflict of interest: None}

\section{References}

1. Barnwell SL, Halbach VV, Dowd CF, et al: A variant of arteriovenous fistulas with in the wall of dural sinuses: Results of combined surgical and endovascular therapy. J Neurosurg 1991;74: 199-204.

2. Chan HY, Cheng KM, Lo MW, Chan CM, Cheung YL. A treatable cause of dementia intracranial dural arteriovenous fistula. HongKong Med J, 2006;12:74-6.

3. Robert WH, Linda JB, Mary S, Eugene SF, Dural arteriovenous fistulas of the craniocervical junction. Skull base surgery 1999; 9(1):

4. Awad I, Little J, Akrawi W, Ahl J. Intracranial dural arteriovenous malformations: factors predisposing to an aggressive neurological course. J Neurosurg 1990 ;72:839850

5. Cognard C, Gobin Y, Pierot L, et al. Cerebral dural arteriovenous fistulas: Clinical and angiographic correlation with a revised classification of venous drainage. Radiology 1995;194:671- 680

6. Hirok K, Yuzo H, Mika O, et al; Treatment of Intracranial Dural Arteriovenous Fistulas: Current Strategies Based on Location and Hemodynamics, and Alternative Techniques of Transcatheter Embolization. Radio Graphics 2004;24:1637-1653.

7. Borden JA, Wu JK, Shucart WA: A proposed classification for spinal and cranial arteriovenous fistulous malformation and implications for treatment. J Neurosurg 1995;82:166179.

8. Chaloupka JC: Endovascular therapy of dural arteriovenous fistula, Semin Intervent Radiology 1994;11:1-13.

9. Cognard C, Gogin YP, Pierot L, et al: Cerebral dural arteriovenous fistulas: clinical and angiographic correlation 
with a revised classification of venous drainage. Radiology 1995, 194:671-680.

10. Duckwiler G: Dural arteriovenous fistula. Neuroimag Cli North Am 1992;2:291-307.

11. Stephan M, Karl OL, German A et al, Arterialization of Cerebral Veins on Dynamic MDCT Angiography:A possible sign of a Dural Arteriovenous Fistula. AJR 2005;184. 13131316.

12. Newton TH, Cronqvist S, Involvement of dural arteries in intracranial arteriovenous malformations. Radiology 1969;93:1071-8.

13. Obrardor S, Soto M, Silvela J:Clinical syndromes of arteriovenous malformations of the transverse sigmoid sinus. J Neurol Neurosurg Psychiatry 1975;38:436-451.

14. Osborn AG: Intracranial vascular malformations. Indiagnostic Neuroradiology. St. Louis: MosbyYtear Book, 1994:284-329.

15. Lasjaunias P, Chiu M, Ter Brugge K, Tolia A, Hurth M, Bernstein M. Neurological manifestations of intracranial dural arteriovenous malformations. J Neurosurg 1986;64:724-39.

16. Padmanabhan R, Stacey R, Wimalaratna S, Kuker W: Dural arteriovenous fistula causing primary intraventricular haemorrhage. Br J Radiol 2008;81:e44-e47.

17. Will A, Peter W; Intracranial dural arteriovenous fistulae. ACNR 2007;7(3):10-12.

18. Chaloupka JC, Endovascular therapy of dural arteriovenous fistula. Semin Intervent Radiol 1994;11:1-13.

19. Davies MA, TerBrugge K, Willinsky R, et al: The validity of classification for the clinical presentation of intracranial dural arteriovenous fistulas. J Neurosurgery 1996; 85:830837.

20. Chaloupka JC, Goller D, Goldberg RA, et al: True anatomic compartmentalization of cavernous sinus in a patient with bilateral cavernous dural arteriovenous fistulae : an unusual diagnostic and therapeutic challenge. J Neurosurg 1993;79:592-595.

21. Albright AL, Latchaw RE, Price RA: Posterior dural arteriovenous malformations in infancy. Neurosurgery1983; $13: 129-135$

22. Borden JA, Wu JK, Shucart WA: A proposed classification for spinal and cranial dural arteriovenous fistulous malformations and implications for treatment. J Neurosurg 1995; 82:166-179.

23. Chaudhary MY, Sachdev VP, Cho SH, et al: Dural arteriovenous malformation of the major venous sinuses: Anacquired lesion. Am J Neuroradiol 1998; 3:13-19.
24. Terada T, Higashida RT, Halbach VV, et al; Development of acquired arteriovenous fistula in rats due to venous hypertention. J Neurosurg 1994; 80:884-889.

25. Folkman J, D Amore PA: Blood vessels formation, what is it’s molecular basis. Cell 1996; 82:1153-1155.

26. Folkman J: Seminars in medicine of the brain Israel Hospital, Boston: Clinical applications of research on angiogenesis; $N$ Engl J Med 1995;333:1757-1765.

27. Cao Y, Linden P, Shima D, et al: In vivo angiogenic activity and hypoxia induction of heterodimers of placenta growth factor/vascular endothelial growth factor. J Clin Invest 1996;98: 2507-2511.

28. Chang E, Boyd A, Nelson CC, et al: successful treatment of infentile hemangiomas with interferon-alpha-2b. J Pediatr Hematol Oncol 1997;19:237-244.

29. Nishijima M, Takaku A, Endo S, et al: Etiological evaluation of dural arteriovenous malformation of the lateral and sigmoid sinuses based on histopathological examinations. J Neurosurg, 1992; 76:600-606.

30. Hinokuma K, Ohama E, Ikuta F, et al: Dural arteriovenous malformation with abnormal parenchymal vessels: an autopsy study. Acta Neuropathol 1990; 80:656-659.

31. Jellema K, Tijssen CC, Gijin JV: Spinal dural arteriovenous fistulas, a congestive myelopathy that initially mimics a perifheral nerve disorder. Brain 2006; 129: 3150-3164.

32. Graed DA, Dolman CL: Radiological and pathological aspects of dural arteriovenous fistulas. J Neurosurg 1986; 64:962-967.

33. Djindjian R, Merland JJ: Super-Selective arteriography of the external carotid artery. Berlin, SpringerVerlag, 1978.

34. Djindjian M, Djindjian R, Rey A, Hurth M, Houdart R. Intradural extramedullary spinal arteriovenous malformations fed by the anterior spinal artery. Surg Neurol 1977; 8:85-93.

35. Yesim A, Funda A, Ismail O, Berrin D: Intracranial Dural Arteriovenous Fistula Draining into Spinal Perimedullary Veins: A Rare Cause of Myelopathy. J Korean Med Sci 2006; 21: 958-62.

36. Tsung J W, Jieh R J, Lin C W, Yung F S, Luke L K L: Ophthalmic Manifestations of Intracranial Dural Arteriovenous Fistula - Report of Four Cases. Tzu Chi Med J 2005;17(2):93-97.

37. Awad IA, Little RJ, Akrawi WP, Ahl J. Intracranial dural arteriovenous malformations: factors predisposing to an aggressive neurological course. J Neurosurg 1990:72;839-50.

38. Satomi J, van Dijk JMC, TerBrugge K, Willinsky RA, Wallace MC. Benign cranial dural arteriovenous fistulas: outcome of conservative management based on the natural history of the lesion. J Neurosurg 2002:97;767-70. 
39. Stephan M, Karl O L, German A, et al: Arterialization of Cerebral Veins on Dynamic MDCT Angiography: A Possible Sign of a Dural Arteriovenous Fistula. AJR 2005;184:13131316.

40. Stephan G W, Deniz B, Philippe L, Bongartz G, et al: Cerebral Dural Arteriovenous Fistulas: Detection by Dynamic MR Projection Angiography. AJR 2000;174:12931295.

41. Likai T, Jiann SJ, Hung JW, et al: Diagnosis of Intracranial Dural Arteriovenous Fistulas by Carotid Duplex Sonography. J Ultrasound Med 2004, 23:785-791.

42. Ishii K, Goto K, Ihara K, et al: High risk dural arteriovenous fistulae of transverse and sigmoid sinuses; Am J Neuroradiology 1988, 8:1113-1121.

43. Luciani A, Houdart E, Mounayer C, Saint Maurice JP, Merland JJ. Spontaneous closure of dural arteriovenous fistulas: report of three cases and review of the literature. Am J Neuroradiol 2001; 22:992-996.

44. O’Leary S, Hodgson TJ, Coley SC, Kemeny AA, Radatz MW. Intracranial dural arteriovenous malformations: results of stereotactic radiosurgery in 17 patients. Clin Oncol (R Coll Radiol) 2002; 14: 97-102.

45. Maruyama K, Shin M, Kurita H, Tago M, Kirino T. Stereotactic radiosurgery for dural arteriovenous fistula involving the superior sagittal sinus: case report. J Neurosurg 2002; 97:481-483.

46. Friedman JA, Pollock BE, Nichols DA, Gorman DA, Foote RL, Stafford SL. Results of combined stereotactic radiosurgery and transarterial embolization for dural arteriovenous fistulas of the transverse and sigmoid sinuses. J Neurosurg 2001; 94: 886-891.

47. Kawaguchi S, Sakaki T, Morimoto T, Hoshida T, Nakase H. Surgery for dural arteriovenous fistula in superior sagittal sinus and transverse sinus. J Clin Neurosci 2000; 7:47-49.
48. Jun S K, MD, Chang W R, Jae S B, et al: Transcranial Approach for Arterial Embolization of Dural Arteriovenous Fistula Within the Wall of the Superior Sagittal Sinus : A Case Report; Neurointervention 2007;2:117-121

49. Roy D, Raymond J. The role of transvenous embolization in the treatment of intracranial dural arteriovenous fistulas. Neurosurgery 1997; 40: 11331144.

50. Klisch J, Huppertz HJ, Spetzger U, Hetzel A, Seeger W, Schumacher M. Transvenous treatment of carotid cavernous and dural arteriovenous fistulae: results for 31 patients and review of the literature. Neurosurgery 2003; 53:836-857.

51. Houser OW, Campbell JK, Campbell RJ, et al: Arteriovenous malformation affecting the transverse dural sinus-an acquired lesion. Mayo Clin Proc 1979; 54:651-661.

52. Nelson PK, Russell SM, Woo HH, Alastra AJ, Vidovich DV. Use of a wedged microcatheter for curative transarterial embolization of complex intracranial dural arteriovenous fistulas: indications, endovascular technique, and outcome in 21 patients. J Neurosurg 2003; 98:498-506.

53. Tomak PR, Cloft HJ, Kaga A, Cawley CM, Dion J, Barrow DL. Evolution of the management of tentorial dural arteriovenous malformations. Neurosurgery 2003; 52:750 762.

54. Troffkin NA, Graham CB III, Berkmen T, Wakhloo AK. Combined transvenous and transarterial embolization of a tentorial-incisural dural arteriovenous malformation followed by primary stent placement in the associated stenotic straight sinus: case report. J Neurosurg 2003; 99:579-583.

55. Robert DB, Kelly DF, Fredric BM, et al: Natural History, Evaluation, and Management of Intracranial Vascular Malformations. Mayo Clin Proc. 2005 ;80(2) :269-281.

56. Lawton MT, Chun J, Wilson CB, Halbach VV. Ethmoidal dural arteriovenous fistulae: an assessment of surgical and endovascular management. Neurosurgery 1999; 45:805-811.

57. Michael F, Paul K, William TC. Interpositional Dural Graft Technique for the Treatment of Dural Arteriovenous Fistulas. Neurosurg Focus. 2007;22(3):1-4. 